\section{State-dependent effects of alcohol on} autonomic orienting responses*

\author{
BARBARA J. POWELL, DONALD W. GOODWIN, CYNTHIA L. JANES \\ and HASKEL HOINE \\ Malcolm Bliss Mental Health Center, St. Louis, Mo. 63014 \\ and \\ Washington University School of Medicine, St. Louis, Mo. 63110
}

The effects of alcohol and change of state on habituation of the orienting responses of skin potential, finger pulse volume, and heart rate in adult males were studied. State-dependent effects of alcohol on these responses were demonstrated, together with a response-depressing effect of alcohol.

Autonomic "orienting" responses (ORs) occur upon presentation of novel stimuli (Sokolov, 1963). After a number of stimulus presentations, the OR decreases in magnitude and eventually drops out or "habituates." If, however, either the qualitative or quantitative aspects of the original stimulus situation are changed, ORs return.

To date, most studies of habituation have involved manipulation of external stimuli. Little is known about the effect on habituation of varying the internal state of the organism. One way in which the internal environment can be altered is with drugs. Overton (1966), Storm, Caird, \& Korbin (1967), Goodwin, Powell, Stern, Bremer, \& Hoine (1969), and Tarter (1970) have observed that certain responses acquired by animals and humans in an alcohol state transfer better to subsequent alcohol states than to a sober "changed" state. This phenomenon has been referred to as a state-dependent or dissociative effect. The present study investigated the effects of alcohol and change of state on habituation of orienting responses in normal adult males. The psychophysiological measures investigated included skin potential, finger pulse volume, and heart rate.

\section{METHOD}

The Ss were 32 male freshman medical students paid to participate in two experimental sessions separated by $24 \mathrm{~h}$. Ss were assigned randomly to one of four conditions: no alcohol (sober) on Days 1 and 2 (SS); alcohol on Days 1 and 2 (AA); no alcohol on Day 1, alcohol on Day 2 (SA); and alcohol on Day 1, no alcohol on Day 2 (AS). Depending on body weight, Ss in the alcohol conditions consumed between 8 and $10 \mathrm{oz}$ of 80-proof vodka, diluted in a soft drink, over a

* Supported, in part, by PHS Research Grants $\mathrm{MH}-09247$ and $\mathbf{M H}-13002$, Training Grants MH-07081 and MH-05804, and a Research Scientist Derelopment Award, No. $11 \mathrm{H}-47325$, from the National Institute of Mental Health (Dr. Goodwin). front of them. The moderately intense $600-\mathrm{Hz}$ tone was presented via a BRS TRS-3 programmer. Stimulation consisted of $2015 \mathrm{sec}$ trials presented at an average intertrial interval of $30 \mathrm{sec}$ (range: $10-60 \mathrm{sec}$ ).

The following methods were used to measure ORs: A skin potential OR (SP OR) was defined as a change in potential of at least $.1 \mathrm{mV}$, occurring $1-4 \mathrm{sec}$ following stimulus onset and beginning with $.5 \mathrm{sec}$ of a given S's modal latency. The pulse volume OR (PV OR) was defined as a vasoconstriction of at least $20 \%$, occurring $1.5 \mathrm{sec}$ following stimulus onset and beginning within 1 sec of a fiven $S$ 's modal latency. Heart rate ORs (HR OR) were measured according to the method of Lang \& Hnaitow (1962), i.e., subtracting the slowest HR among the 20 beats following stimulus onset from the fastest of the first 6 beats following stimulus onset.

\section{RESULTS AND DISCUSSION}

The results were analyzed according to the effects of alcohol per se and the effects of changes in alcohol state on habituation and responsivity of the psychophysiological measures. The nonparametric Mann-Whitney U test (Siegel, 1956) was employed to evaluate response effects of alcohol.

The number of skin potential responses on both days was not significantly different for the alcohol and nonalcohol Ss. For the heart-rate ORs, alcohol Ss responded less than nonalcohol Ss only on Day 2 (U Day $2=10, p<.05$; $U$ Day $1=41$, n.s.). Pulse volume responsiveness was more clearly affected in that a significant response reduction by alcohol was found on both days ( $U$ Day $1=51, p<.025$, U Day $2=28$, $\mathrm{p}<.001$ ).

State-dependent effects of alcohol were also demonstrated, with the strongest effect manifested in within-S correlations for Day 1 and Day 2 responses. These results are presented in Table 1. As noted, correlations for the same-state groups were significant for all measures, while corresponding

Table 1

OR Correlational Analyses for Same- and Changed-State Groups*

\begin{tabular}{|c|c|c|c|c|c|c|c|c|c|}
\hline & \multicolumn{3}{|c|}{ Skin Potential } & \multicolumn{3}{|c|}{ Pulse Volume } & \multicolumn{3}{|c|}{ Heart Rate } \\
\hline & $\mathrm{x}$ & $\mathrm{r}^{\mathrm{a}}$ & $\mathrm{p}$ & $\mathrm{s}$ & $\mathrm{r}^{\mathrm{a}}$ & $\mathrm{p}$ & $\mathbf{N}$ & $\mathrm{r}^{\mathrm{b}}$ & $\mathbf{p}$ \\
\hline \multicolumn{10}{|l|}{ Same State } \\
\hline SS & 8 & .68 & .05 & 7 & .90 & .01 & & & \\
\hline$A A$ & 8 & .94 & .01 & 7 & .66 & n.s. & & & \\
\hline$(\mathrm{SS}+\mathrm{AA})$ & 16 & .86 & .01 & 14 & .79 & .01 & 8 & .75 & .025 \\
\hline \multicolumn{10}{|c|}{ Changed State } \\
\hline $\mathrm{SA}$ & 8 & .22 & n.s. & 7 & -.06 & n.s. & & & \\
\hline AS & 8 & -.17 & n.s. & 7 & .54 & n.s. & & & \\
\hline$(S A+A S)$ & 16 & .05 & n.s. & 14 & -.42 & n.s. & 6 & .44 & n.s. \\
\hline
\end{tabular}

aspearman correlations: bPearson correlations

* Reduced numbers of obseriations resulted from equipment or recording difficulties. 
values for the changed groups were not. Inter-S order with respect to responsivity tended to be maintained when the drug state was maintained so that for these Ss, day-to-day level of psychophysiological responding was more predictable than for changed-state Ss. Change in state served to increase response frequency for some Ss, while decreasing it for others. These results provide evidence for state-dependent effects on the psychophysiological level.

Results from habituation measures suggest that same-state Ss tended to habituate more to the stimulus situation than changed-state Ss. OR habituation was measured by comparing the number of responses a given $\mathbf{S}$ emitted on Day 1 to those emitted on Day 2. Thirteen of the 16 same-state group manifested more skin potential responses on the first day than on the second, while only half of the changed-state group did so. Comparable values were obtained for pulse volume. Though these results suggest a tendency toward differential habituation, neither differences for skin potential nor pulse volume were significant. The failure of this effect to reach significance may be attributable in part to the response-depressing effect of alcohol masking the state-dependent effect. For example, on both the skin potential and pulse volume measures, most $(12 / 16$ and 11/14) same-state Ss responded more on the first day, while the majority (12/16 and 14/14) of changed-state Ss responded more on the nonalcohol day. Thus, those Ss who changed drug state responded more on Day 2 only if they were in the nonalcohol condition. Heart-rate habituation appeared unaffected by alcohol in that half the $S s$ in each group manifested an increase in HR ORs while half did not.

In summary, the present study suggests that state-dependent effects can be demonstrated in certain psychophysiological responses. However, the technical problems of drug-induced response depression make the measurement of state-dependent effects in psychophysiological systems more difficult than with cognitive tasks. The utilization of a more intense stimulus than was employed in this investigation might augment autonomic responsivity so that depressant and state-dependent effects would become more separable.

\section{REFERENCES}

GOODWIN, D. W., POWELL, B. J. BREMER, D.. HOINE, H., \& STERN, J. Alcohol and recall: State-dependent effects in man. Science, 1969, 163. 1358-1360.

LANG, P.. \& HNAITOW, J. Stimulus repetition and the heart rate response. Journal of Comparative \& Physiological Psychology, 1962.55, 781.785.

OVERTON, D. A. State-dependent learning produced by depressant and atropine-like drugs. Psychopharmacologia, 1966, 10, 6-31.

SIEGEL, S. Nonparametric statistics for the behailaral sciences. New York: McGraw-Hill, 1956.

SOKOLOV, E. N. Higher nervous function The orienting reflex. In V. E. Hall (Ed.) Annual revieu of physiology. Vol. 25 $P$ alo Alto: Annual Reviews, 1963. Pp. 545-568.

STORM, T. CAIRD, W. K. \& KORBIN, E. The effects of alcohol on rote verbal learning and retention. Psychonomic Science, 1967, 9, 43-44.

TARTER. R. Dissociate effects of ethyl alcohol. Psychonomic Science, 1970, 20 , 342-343. 